\title{
BMJ Open Association between smoking and in- hospital mortality in patients with acute myocardial infarction: results from a prospective, multicentre, observational study in China
}

Chenxi Song, ${ }^{1}$ Rui Fu, ${ }^{1}$ Kefei Dou, ${ }^{1}$ Jingang Yang, ${ }^{1}$ Haiyan Xu, ${ }^{1}$ Xiaojin Gao, ${ }^{1}$ Hao Wang, ${ }^{1}$ Shuai Liu, ${ }^{1}$ Xiaoxue Fan, ${ }^{2}$ Yuejin Yang ${ }^{1}$

To cite: Song C, Fu R, Dou K, et al. Association between smoking and in-hospital mortality in patients with acute myocardial infarction: results from a prospective, multicentre, observational study in China. BMJ Open 2019;9:e030252. doi:10.1136/ bmjopen-2019-030252

- Prepublication history and additional material for this paper are available online. To view these files, please visit the journal online (http://dx.doi org/10.1136/bmjopen-2019030252).

CS and RF contributed equally. $\mathrm{KD}$ and $\mathrm{YY}$ contributed equally.

Received 10 March 2019

Revised 29 July 2019

Accepted 30 July 2019
D) Check for updates

(C) Author(s) (or their employer(s)) 2019. Re-use permitted under CC BY-NC. No commercial re-use. See rights and permissions. Published by BMJ.

For numbered affiliations see end of article.

Correspondence to

Dr Yuejin Yang;

yangyjfw@126.com

\section{ABSTRACT}

Introduction Smoking is a well-established risk factor for cardiovascular disease. However, the effect of smoking on in-hospital mortality in patients with acute myocardial infarction (AMI) who are managed by contemporary treatment is still unclear.

Methods A cohort study was conducted using data from the China AMI registry between 2013 and 2016. Eligible patients were diagnosed with AMI in accordance with the third universal definition of MI. Propensity score (PS) matching and multivariable logistic regression were used to control for confounders. Subgroup analysis was performed to examine whether the association between smoking and in-hospital mortality varies according to baseline characteristics.

Results A total of 37614 patients were included. Smokers were younger and more frequently men with fewer comorbidities than non-smokers. After PS matching and multivariable log regression analysis were performed, the difference in in-hospital mortality between current smokers versus non-smokers was reduced, but it was still significant ( $5.1 \%$ vs $6.1 \%, \mathrm{p}=0.0045$; adjusted OR 0.78 , $95 \% \mathrm{Cl} 0.69$ to $0.88, p<0.001)$. Among all subgroups, there was a trend towards lower in-hospital mortality in current or ex-smokers compared with non-smokers.

Conclusions Smoking is associated with lower in-hospital mortality in patients with AMI, even after multiple analyses to control for potential confounders. This 'smoker's paradox' cannot be fully explained by confounding alone. Trial registration number NCT01874691.

\section{INTRODUCTION}

Smoking is a well-established risk factor of cardiovascular disease. ${ }^{12}$ However, some previous studies have shown that smokers have a better outcome than do non-smokers following acute myocardial infarction (AMI). This phenomenon is referred to as 'smoker's paradox'. This phenomenon was first introduced in the 1970s, when Helmers found that smokers had a lower risk of mortality than did non-smokers. ${ }^{3}$ Some subsequent

\section{Strengths and limitations of the study}

- This study used data from a large-scale multicentre registry in a contemporary era of percutaneous intervention.

- We used propensity score matching and multivariable logistic regression model to adjust for confounders, which ensured the robustness of our conclusion.

- The current study did not include data on patients who died before hospitalisation, which may have caused index event bias (a type of selection bias).

- The current study did not adjust for unmeasured confounders.

studies also showed smoker's paradox in patients with acute coronary syndrome. ${ }^{4}$ This paradox may be explained by differences in baseline characteristics between smokers and non-smokers. ${ }^{5}$ Additionally, the antiplatelet response may differ according to smoking status because of the effect of smoking on pharmacodynamics of clopidogrel therapy. ${ }^{6}$ Notably, most studies regarding smoker's paradox were conducted in the era of thrombolysis, while the association between smoking and in-hospital mortality in patients who are treated with the percutaneous intervention (PCI) remains controversial. Some studies have reported that the difference in in-hospital mortality was not significant between smokers and non-smokers after accounting for age and other baseline characteristics. $^{7-13}$ Other studies reported that smokers had a lower in-hospital mortality rate compared with non-smokers, even after adjustment for potential confounders (smoker's paradox) ${ }^{14-18}$

Examining the true effect of smoking on outcome among contemporary patients 
with AMI is important. On one hand, the phenomenon of 'smoking paradox' has a negative effect on quitting smoking in a public health perspective. On the other hand, if smoker's paradox still exists in the contemporary era of PCI, the biochemical basis for this phenomenon should be investigated. This investigation may promote the development of novel therapy for myocardial protection.

This study aimed to assess how smoking affects the in-hospital mortality of patients receiving contemporary management of AMI.

\section{METHODS}

\section{Data source}

A cohort study was conducted using data from the China AMI (CAMI) registry between 01 January 2013 and 31 January 2016. A detailed description of the registry design was published previously. ${ }^{19}$ Briefly, the CAMI registry was a prospective, multicentre, observational registry. The project included Chinese patients with AMI and data were collected on patients' characteristics, treatments and outcomes. A total of 108 hospitals covering a broad geographic region participated in the project. This assured a good representation of all of the patients with AMI in China and reduced selection bias. ${ }^{19}$ Written informed consent was obtained from each patient who was included in the study. If the patient was not able to communicate, informed consent was obtained from a family member. The study protocol conforms to the ethical guidelines of the 1975 Declaration of Helsinki.

\section{Study population}

We included the study population from the CAMI registry. Eligible patients were diagnosed with AMI and within 7 days of ischaemic symptoms. Diagnostic criteria of AMI were in accordance with the third universal definition of MI. ${ }^{20}$ We excluded patients who were aged $<18$ or $>100$ years, and those with missing or invalid data on sex, admission diagnosis and smoking status.

Data were extracted by trained researchers using standard definitions to reduce measurement and reporting bias. These data included age, sex, height, weight, clinical presentation (symptoms, ST-segment elevation, anterior wall MI, blood pressure, heart rate, heart failure, cardiac shock, fatal arrhythmia, cardiac arrest and Killip classification), risk factors (hypertension, hyperlipidaemia and diabetes), comorbidities (heart failure, peripheral vascular disease (PVD), stroke, chronic kidney disease and chronic obstructive pulmonary disease (COPD)), medical history (family history of premature coronary artery disease (CAD), prior angina or MI, prior coronary intervention and prior coronary artery bypass grafting $(\mathrm{CABG}))$, initial reperfusion strategy (primary PCI, thrombolysis and conservative therapy), laboratory results (creatinine, haemoglobin and left ventricular ejection fraction (LVEF)) and in-hospital outcome.
Patient and public involvement

We did not involve patients or the public in our work.

\section{Definition of variables}

All patients were divided into three groups according to smoking status. Current smokers were defined as those who smoked within 1 month before registration. Ex-smokers were defined as those who quitted smoking for at least 1 month. Non-smokers were defined as those who never smoked. Standard definitions of the medical history and physical examination elements were well described in the American College of Cardiology and American Heart Association (ACC/AHA) Task Force on Clinical Data Standards and the NCDR-ACTION-GWTG element dictionary. ${ }^{21-23}$ ECGs and echocardiograms were interpreted locally.

The primary endpoint was all-cause in-hospital mortality, which was defined as all-cause death during hospitalisation.

\section{Statistical analysis}

Baseline continuous data are presented as mean $\pm \mathrm{SD}$ or median (25th-75th percentiles) and were compared using one-way analysis of variance. This was followed by the Bonferroni t-test with a corrected $\mathrm{p}$ value of $0.05 / 3$. Categorical data are presented as counts and frequencies and were compared using the $\chi^{2}$ test. Propensity score (PS) matching was used to control for baseline differences. We performed PS matching between current and non-smokers, and between ex-smokers and non-smokers. We used a multivariable logistic regression model to estimate PSs, with smoking as the dependent variable and the following factors as covariates: age, sex, body mass index (BMI), systolic blood pressure, heart rate, admission diagnosis, cardiac arrest, chest pain, ST elevation, anterior wall MI, Killip classification, risk factor (medical

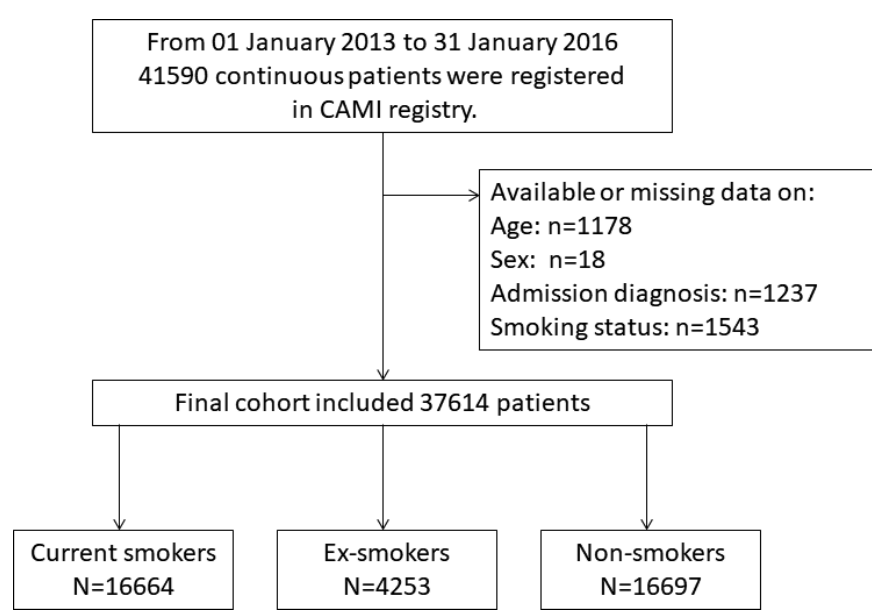

Figure 1 Study flow chart. From January 2013 to January 2016, 41590 continuous patients were registered in CAMI registry. Those aged $<18$ or $>100$ years $(n=1178)$, with missing or invalid data on gender $(n=18)$, admission diagnosis $(n=1237)$ and detailed smoking status $(n=1543)$ were excluded. The final cohort included 37614 patients. CAMI, China acute myocardial infarction. 
history of diabetes, hypertension, hyperlipidaemia, premature family CAD history, heart failure, renal failure and COPD), medical history (previous angina, PCI and CABG), creatinine levels, haemoglobin levels, Global Registry of Acute Coronary Events risk score and primary PCI. These variables were chosen as covariates because the difference in these baseline characteristics reached statistical significance or these variables were previously reported to be associated with patients' outcome.

Matching was performed using the greedy nearest matching algorithm and a 1:1 fashion. The calliper width was equal to 0.01 of the standardised difference of the score. McNemar's and paired t tests were used to compare continuous and categorical variables between the two groups after matching. For each variable in the PS model, we computed the standardised difference between the two groups, with a standardised difference less than 0.1 indicating good balance.

The stepwise selection method was used to compare in-hospital mortality across different groups. Baseline characteristics that significantly differed across the groups and those of clinical importance were included in the

\begin{tabular}{|c|c|c|c|c|}
\hline Variable & Current smokers ( $n=16664)$ & Ex-smokers $(n=4253)$ & Non-smokers ( $n=16$ 697) & $P$ value \\
\hline Age (years) & $57.99 \pm 11.81$ & $66.49 \pm 11.50$ & $66.59 \pm 11.82$ & $<0.0001$ \\
\hline Male & 15 616/16 664 (93.7\%) & $3997 / 4253$ (94.0\%) & $8317 / 16697$ (49.8\%) & $<0.0001$ \\
\hline $\mathrm{BMI}\left(\mathrm{kg} / \mathrm{m}^{2}\right)$ & $24.39 \pm 2.87$ & $23.95 \pm 2.84$ & $23.98 \pm 2.95$ & $<0.0001$ \\
\hline ST elevation on ECG & 12 044/16 330 (74.3\%) & $2725 / 4185$ (65.7\%) & 10 822/16 374 (66.7\%) & 0.2338 \\
\hline $\mathrm{SBP}(\mathrm{mm} \mathrm{Hg})$ & $127.82 \pm 24.69$ & $129.71 \pm 25.17$ & $130.58 \pm 25.97$ & $<0.0001$ \\
\hline Heart rate (bpm) & $76.74 \pm 17.40$ & $79.85 \pm 19.82$ & $79.47 \pm 18.89$ & $<0.0001$ \\
\hline $\begin{array}{l}\text { Heart failure on } \\
\text { admission }\end{array}$ & $1851 / 16608(11.1 \%)$ & $817 / 4227(19.2 \%)$ & $3016 / 16620(18.1 \%)$ & 0.0781 \\
\hline Cardiac shock & 512/16 597 (3.1\%) & $175 / 4227(4.1 \%)$ & 658/16 $614(3.9 \%)$ & 0.5962 \\
\hline Killip classification & & & & $<0.0001$ \\
\hline I & 13 332/16 577 (80.4\%) & $2877 / 4215(68.3 \%)$ & 11 906/16 568 (71.9\%) & \\
\hline II & 2272/16 577 (13.7\%) & $799 / 4215(19.0 \%)$ & $2892 / 16568$ (17.5\%) & \\
\hline III & 472/16 577 (2.8\%) & $324 / 4215$ (7.7\%) & 951/16 568 (5.7\%) & \\
\hline IV & 501/16 577 (3.0\%) & $215 / 4215$ (5.1\%) & $819 / 16568$ (4.9\%) & \\
\hline
\end{tabular}

Comorbidities

\begin{tabular}{lcccr} 
Hypertension & $7288 / 16653(43.8 \%)$ & $2328 / 4251(54.8 \%)$ & $9434 / 16693(56.5 \%)$ & 0.0401 \\
\hline Hyperlipidaemia & $1329 / 16640(8.0 \%)$ & $367 / 4247(8.6 \%)$ & $1020 / 16679(6.1 \%)$ & $<0.0001$ \\
\hline Diabetes & $2451 / 16635(14.7 \%)$ & $924 / 4242(21.8 \%)$ & $3893 / 16672(23.4 \%)$ & 0.0295 \\
\hline PVD & $100 / 16611(0.6 \%)$ & $49 / 4234(1.2 \%)$ & $115 / 16642(0.7 \%)$ & 0.0035 \\
\hline Heart failure & $177 / 16628(1.1 \%)$ & $199 / 4235(4.7 \%)$ & $528 / 16638(3.2 \%)$ & $<0.0001$ \\
\hline Stroke & $1176 / 16616(7.1 \%)$ & $570 / 4237(13.5 \%)$ & $1666 / 16648(10.0 \%)$ & $<0.0001$ \\
\hline COPD & $277 / 16664(1.7 \%)$ & $191 / 4253(4.5 \%)$ & $277 / 16697(1.7 \%)$ & $<0.0001$ \\
$\begin{array}{l}\text { Chronic kidney } \\
\text { disease }\end{array}$ & $121 / 16588(0.7 \%)$ & $103 / 4222(2.4 \%)$ & $257 / 16612(1.5 \%)$ & 0.0001 \\
Smoking duration (years) & $30.38 \pm 11.89$ & $26.86 \pm 11.99$ & $\mathrm{NA}$ & $<0.0001$ \\
$\begin{array}{l}\text { Number of cigarettes/ } \\
\text { day }\end{array}$ & $21.23 \pm 11.10$ & $19.13 \pm 10.93$ & $\mathrm{NA}$ & $<0.0001$ \\
Hb (g/L) & $142.15 \pm 17.42$ & $135.38 \pm 19.39$ & $130.18 \pm 19.43$ & $<0.0001$ \\
Creatinine (mg/L) & $37.40 \pm 0.69$ & $37.40 \pm 0.46$ & $37.42 \pm 2.04$ & 0.1842 \\
Primary PCl & $8499 / 16544(51.4 \%)$ & $1566 / 4224(37.1 \%)$ & $6369 / 16579(38.4 \%)$ & 0.1084 \\
P2Y12 inhibitors & 16 086/16 458 (97.7\%) & $4030 / 4186(96.3 \%)$ & $15837 / 16446(96.3 \%)$ & 0.9423 \\
GRACE risk score & $151.43 \pm 33.02$ & $171.34 \pm 35.63$ & $169.61 \pm 35.89$ & $<0.0001$ \\
In-hospital mortality & $614 / 16664(3.7 \%)$ & $306 / 4325(7.2 \%)$ & $1450 / 16679(8.7 \%)$ & 0.0015 \\
\hline
\end{tabular}

Data are presented as mean $\pm S D$ or frequencies.

BMI, body mass index; COPD, chronic obstructive pulmonary disease; GRACE, Global Registry of Acute Coronary Events; Hb, haemoglobin;NA, not available; PCl, percutaneous intervention; PVD, peripheral vascular disease; SBP, systolic blood pressure. 
model. These variables were the same as those used for propensity matching. A $p$ value $<0.1$ was used as the entry criterion and $<0.05$ was used as the removal criterion. To determine whether the association between smoking and in-hospital mortality varied according to baseline patients' characteristics, we performed the same multivariable logistic analysis in subgroups that were stratified by age, sex, BMI, presence or absence of hypertension, diabetes, hyperlipidaemia, heart failure, prior angina, MI or coronary intervention and admission diagnosis. A two-sided $p$ value $<0.05$ was considered significant. For the interaction test, a $p$ value $<0.1$ was considered significant. For all variables included in our study, less than $2 \%$ of the data were missing. We used complete-case analysis to deal with missing data. ${ }^{24}$ Patients with missing data were excluded from the analysis. We presented data as 'counts/total numbers available (frequencies)' for categorical variables.

\section{RESULTS}

\section{Baseline characteristics}

From 01 January 2013 to 31 January 2016, a total of 41590 continuous patients were registered in the CAMI registry. We excluded 1178 patients aged $<18$ or $>100$ years, and those with missing or invalid data on sex $(n=18)$, admission diagnosis $(n=1237)$ and detailed smoking status $(n=1543)$. The final cohort included 37614 patients (figure 1).

Baseline characteristics before matching are presented in table 1. A total of 16664 (44.3\%) patients were current smokers, $843(2.2 \%)$ quit smoking before or at 1 year, 3410 $(9.1 \%)$ quit smoking after 1 year and 16697 (44.4\%) were non-smokers. Current smokers were younger $(57.99 \pm 11.81$ vs $66.59 \pm 11.82$ years $)$ and had a higher BMI $(24.39 \pm 2.87$ vs $23.98 \pm 2.95 \mathrm{~kg} / \mathrm{m}^{2}$ ) compared with non-smokers. The proportion of men $(93.7 \%$ vs $49.8 \%)$ and Killip class I ( $80.4 \%$ vs $71.9 \%$ ) was higher in current smokers compared with non-smokers. Compared with non-smokers, current smokers were less likely to have hypertension, diabetes, heart failure, stroke or chronic kidney disease, but more likely to have hyperlipidaemia. Among ex-smokers, the proportions of male sex, hyperlipidaemia, heart failure, PVD and stroke were higher than those of current smokers. Ex-smokers also showed a trend towards old age and a low proportion of hypertension and diabetes than did current smokers, but these differences were less significant compared with the differences between current and non-smokers.

\section{In-hospital outcomes}

Overall, 2370 patients died before discharge. There were $614(3.7 \%)$ deaths in the current smoker group, 306 (7.2\%) deaths in the ex-smoker group and $1450(8.7 \%)$ deaths in the non-smoker group. Causes of mortality are presented in online supplementary table 1 . The unadjusted OR for in-hospital mortality was $0.4(95 \%$ CI 0.37 to $0.44, \mathrm{p}<0.0001)$ in current smokers and 0.82 (95\% CI 0.72 to $0.93, \mathrm{p}=0.0018$ ) in ex-smokers relative to non-smokers (table 2). After adjustment for potential confounders, current smoking status was significantly associated with lower in-hospital mortality relative to non-smokers (adjusted OR 0.78, 95\% CI 0.69 to 0.88 , $\mathrm{p}<0.001$ ) (table 2). No difference in in-hospital mortality was detected between ex-smokers and non-smokers (OR $0.89,95 \%$ CI 0.77 to $1.04, \mathrm{p}=0.1443$ ).

\section{PS matching}

Before PS matching, there were differences in almost all baseline variables among the different groups (table 1). To control for potential confounding, we matched 8552 current smokers with 8552 non-smokers, as well as 4142 ex-smokers and 4142 non-smokers (online supplementary table 2). The standardised differences were less than $10.0 \%$ for all variables after matching, which indicated a good match between two groups. After PS matching, current smokers still had lower in-hospital mortality than did non-smokers ( $5.1 \%$ vs $6.1 \%, \mathrm{p}=0.0045)$, but the difference in in-hospital mortality was not significant between ex-smokers and non-smokers $(7.0 \%$ vs $7.4 \%, \mathrm{p}=0.5198)$ (online supplementary table 3 ).

\section{Subgroup analysis}

Subgroup analysis indicated significant interactions between smoking status and age $\left(\mathrm{p}_{\text {interaction }}: 0.0986\right)$, sex $\left(\mathrm{p}_{\text {interaction }}: 0.0163\right), \operatorname{LVEF}\left(\mathrm{p}_{\text {interaction }}: 0.0149\right)$, previous MI $\left(\mathrm{p}_{\text {interaction }}: 0.0557\right)$ and previous heart failure $\left(\mathrm{p}_{\text {interaction }}\right.$ : 0.0086 ) for in-hospital mortality (table 3 ). However, there

Table 2 Association between smoking and in-hospital mortality

\begin{tabular}{llllr}
\hline & OR $(95 \%$ Cl) & & \\
\cline { 2 - 4 } Smoking status & Unadjusted & Adjusted* & PS matching & P value† \\
\hline Current smokers versus non-smokers & $0.40(0.37$ to 0.44$)$ & $0.78(0.69$ to 0.88$)$ & $0.80(0.69$ to 0.92$)$ & $<0.0001$ \\
Ex-smokers versus non-smokers & $0.82(0.72$ to 0.93$)$ & $0.89(0.77$ to 1.04$)$ & $1.03(1.02$ to 1.04$)$ & 0.1443 \\
\hline
\end{tabular}

${ }^{*}$ Adjusted for age, gender, BMI, systolic blood pressure, heart rate, admission diagnosis, cardiac arrest, chest pain, ST elevation, anterior wall MI, Killip classification, risk factor (medical history of diabetes, hypertension, hyperlipidaemia, premature family CAD history, heart failure, renal failure and COPD), medical history (previous angina, $\mathrm{PCl}$ and $\mathrm{CABG}$ ), creatinine level, haemoglobin level, GRACE risk score and primary $\mathrm{PCl}$. The number of patients included in the adjusted model was 37614.

†Adjusted $\mathrm{p}$ value.

BMI, body mass index; CABG, coronary artery bypass grafting; CAD, coronary artery disease; COPD, chronic obstructive pulmonary disease; GRACE, Global Registry of Acute Coronary Events; MI, myocardial infarction; PCI, percutaneous intervention; PS, propensity score. 
Table 3 Association between smoking and in-hospital mortality according to baseline characteristics

\begin{tabular}{|c|c|c|c|c|}
\hline Baseline characteristics & Current smoker & Ex-smoker & Non-smoker & $\begin{array}{l}P_{\text {interaction }} \\
\text { value }\end{array}$ \\
\hline Age $\geq 55$ years & 0.78 (0.69 to 0.89$)$ & 0.90 (0.77 to 1.05$)$ & Reference & 0.0986 \\
\hline Age $<55$ years & 0.72 (0.53 to 0.99$)$ & 0.85 (0.48 to 1.49$)$ & Reference & \\
\hline Male & 0.78 (0.68 to 0.89$)$ & 0.94 (0.80 to 1.10$)$ & Reference & 0.0163 \\
\hline Female & 0.75 (0.58 to 0.98$)$ & 0.45 (0.26 to 0.77$)$ & Reference & \\
\hline $\mathrm{BMl} \geq 24 \mathrm{~kg} / \mathrm{m}^{2}$ & 0.80 (0.67 to 0.94$)$ & 0.89 (0.71 to 1.12$)$ & Reference & 0.2063 \\
\hline $\mathrm{BMl}<24 \mathrm{~kg} / \mathrm{m}^{2}$ & 0.74 (0.63 to 0.88$)$ & 0.89 (0.73 to 1.10$)$ & Reference & \\
\hline LVEF $\geq 50 \%$ & 0.77 (0.67 to 0.88 ) & $0.98(0.82$ to 1.16$)$ & Reference & 0.0149 \\
\hline LVEF $<50 \%$ & 0.87 (0.68 to 1.11$)$ & 0.74 (0.54 to 1.01$)$ & Reference & \\
\hline Hypertension-Yes & 0.85 (0.72 to 1.00$)$ & 0.96 (0.78 to 1.17$)$ & Reference & 0.4556 \\
\hline Hypertension-No & 0.70 (0.59 to 0.83$)$ & 0.80 (0.64 to 1.01$)$ & Reference & \\
\hline Previous angina - Yes & 0.84 (0.65 to 1.07$)$ & 0.83 (0.62 to 1.12$)$ & Reference & 0.1833 \\
\hline Previous angina - No & 0.76 (0.66 to 0.87$)$ & 0.92 (0.78 to 1.10$)$ & Reference & \\
\hline Previous MI-Yes & 0.67 (0.47 to 0.97$)$ & 0.67 (0.45 to 1.00$)$ & Reference & 0.0557 \\
\hline Previous $\mathrm{Ml}-\mathrm{No}$ & 0.77 (0.68 to 0.87$)$ & 0.91 (0.78 to 1.07$)$ & Reference & \\
\hline Previous $\mathrm{PCl}-$ Yes & 0.95 (0.44 to 2.04$)$ & 1.23 (0.56 to 2.72$)$ & Reference & 0.7975 \\
\hline Previous $\mathrm{PCl}-\mathrm{No}$ & 0.78 (0.69 to 0.88$)$ & 0.89 (0.76 to 1.04$)$ & Reference & \\
\hline Previous HF-Yes & 0.96 (0.57 to 1.60$)$ & 0.85 (0.53 to 1.37$)$ & Reference & 0.0086 \\
\hline Previous HF-No & 0.77 (0.68 to 0.87$)$ & 0.88 (0.76 to 1.03$)$ & Reference & \\
\hline Diabetes-Yes & 0.78 (0.60 to 1.02$)$ & 0.86 (0.63 to 1.18$)$ & Reference & 0.4065 \\
\hline Diabetes-No & 0.77 (0.67 to 0.88$)$ & 0.90 (0.76 to 1.07$)$ & Reference & \\
\hline Hyperlipidaemia-Yes & 0.75 (0.45 to 1.24$)$ & 1.16 (0.66 to 2.03$)$ & Reference & 0.1239 \\
\hline Hyperlipidaemia-No & 0.77 (0.68 to 0.87$)$ & 0.87 (0.74 to 1.02$)$ & Reference & \\
\hline Diagnosis of STEMI & 0.81 (0.71 to 0.93 ) & 0.93 (0.78 to 1.11$)$ & Reference & 0.9700 \\
\hline Diagnosis of NSTEMI & 0.61 (0.48 to 0.78 ) & 0.71 (0.54 to 0.92$)$ & Reference & \\
\hline
\end{tabular}

Adjusted for age, gender, BMI, systolic blood pressure, heart rate, admission diagnosis, cardiac arrest, chest pain, ST elevation, anterior wall MI, Killip classification, risk factor (medical history of diabetes, hypertension, hyperlipidaemia, premature family CAD history, heart failure, renal failure and COPD), medical history (previous angina, $\mathrm{PCl}$ and $\mathrm{CABG}$ ), creatinine level, haemoglobin level, GRACE risk score and primary $\mathrm{PCl}$.

BMI, body mass index;CABG, coronary artery bypass grafting; CAD, coronary artery disease; COPD, chronic obstructive pulmonary disease; GRACE, Global Registry of Acute Coronary Events; HF, heart failure; LVEF, left ventricular ejection fraction; MI, myocardial infarction;NSTEMI, non-ST-elevation MI; PCl, percutaneous coronary intervention; STEMI, ST-elevation MI.

was a trend towards lower in-hospital mortality in the current or ex-smoker group compared with the non-smoker group.

\section{DISCUSSION}

Our study used data from the CAMI registry, which is the largest contemporary registry of patients with AMI in East Asia. Our major finding was that in patients with AMI, current smokers had lower in-hospital mortality than did non-smokers in the whole population and almost all subgroups, after adjusting for potential confounders using PS matching.

\section{Comparison with previous studies}

Most previous studies were conducted in the thrombolytic era and we only identified four studies that enrolled patients in the current primary PCI era. ${ }^{13} 182526$ Of these four studies, three studies used multivariate regression analysis to control for confounders. Our study results are consistent with those from another large-scale study. ${ }^{18}$ This previous study also showed that among patients with ST-elevation MI who received primary PCI, smokers (including current and ex-smokers) had a lower adjusted in-hospital mortality risk than did non-smokers. In our study, we further separated current and ex-smokers, and used PS matching to comprehensively control for potential confounders. Several mechanisms have been proposed to explain this paradox phenomenon.

First, some studies showed that a suppressive effect of clopidogrel on platelets was greater in smokers than in non-smokers. ${ }^{27-29}$ A potential explanation for this finding is that smoking can enhance in-vivo bioactivation of clopidogrel via increasing induction of cytochrome P450 (CYP1A2 and CYP2B6) and increased active metabolite concentrations of clopidogrel. ${ }^{30} 31$ Therefore, smokers 
may respond better to clopidogrel therapy and consequently have a lower in-hospital mortality rate than non-smokers. Second, smoking was unexpectedly associated with a lower risk of adverse left ventricular remodelling postinfarction. Symons et al performed cardiac MRI at 4 days and 4 months after MI. They found that smokers had an improved LVEF, which was attributable to a decrease in the end-diastolic volume index, but not an increase in the systolic volume index. ${ }^{32}$

However, our results are not consistent with two studies, which found an absence of the smoker paradox after baseline risk adjustment. ${ }^{1326}$ This difference may be related to the selection of the study population and sample size. One previous study enrolled patients with symptomatic CAD, including those who presented with stable or unstable angina, ${ }^{9}$ while we included patients with AMI. Patients with stable angina represent a relatively lower risk group. Therefore, enrolment of this patient subset may affect the association between smoking and mortality. The other study had a small sample size $(n=382)$, and it may not have had sufficient statistical power to detect a difference in mortality between smokers and non-smokers.

\section{Interpretation of our results}

Our results should be interpreted with caution. Although we adjusted for many common confounders, our study was still subject to selection bias as discussed below in the Strengths and limitations of the study box. Our results should not be interpreted as encouraging patients to smoke. Smoking is well-established as an independent risk factor for mortality and recurrent $\mathrm{MI},{ }^{33}$ as well as for subacute stent thrombosis ${ }^{34}$ in the long-term, and patients with coronary heart disease can benefit from cessation of smoking. ${ }^{35}$ Therefore, we still recommend that patients stop smoking. Our results indicated potential mechanisms underlying the protective effect of smoking. Future studies should investigate novel therapies to protect the myocardium by targeting the relevant pathways. Smoking might lead to a chronic ischaemic state (ischaemic preconditioning $)^{36}$; therefore, smokers might have better tolerance for an acute ischaemic event, such as a heart attack. The phenomenon could be investigated by examining whether preconditioning therapy or a brief period of reversible ischaemia can protect the myocardium and improve outcome.

Our subgroup analysis showed a significant interaction between smoking status and age, sex, LVEF, previous MI and previous heart failure. However, currently, we cannot reach the conclusion that these baseline characteristics had a significant effect on the relationship between smoking and in-hospital mortality. This is because there was a similar trend among all subgroups that current smokers and ex-smokers had a lower in-hospital mortality risk compared with non-smokers. A significant $p$ value may be attributed to a different OR value between subgroups of smokers and non-smokers, as well as a large sample size of some of the subgroups.

\section{Limitations}

Our study may have been subject to selection bias. The CAMI registry did not collect data on patients who died before hospitalisation. Failing to account for prehospital deaths may have led to selection bias. The distribution of risk factors was significantly different between smokers and non-smokers. Although we adjusted for known and measured variables, there are likely to be other unmeasured variables leading to selection bias. The CAMI registry was a multicentre, large-scale study that involved more than 100 hospitals. Although a standardised data collection procedure was emphasised, the accuracy of data still greatly depends on the expertise of local investigators. The CAMI registry did not collect detailed data regarding the smoking status. Smoking status might be modified after the onset of MI. However, we asked the patients about their smoking status before the onset of AMI and all patients were enrolled within 7 days of symptom onset. We only assessed the association between smoking and short-term outcome. Future studies are required to investigate this association in the long-term.

\section{CONCLUSIONS}

Our study showed that the in-hospital mortality rate was lower in smokers compared with non-smokers in a large-scale, contemporary cohort representing patients with AMI in China. Our findings indicate that future studies should be performed to further explore the potential biological mechanisms that may explain this phenomenon.

\section{Author affiliations}

${ }^{1}$ Coronary Heart Disease Center, Fuwai Hospital, Chinese Academy of Medical Sciences, National Center for Cardiovascular Diseases and Peking Union Medical College, Beijing, China

${ }^{2}$ Medical Research \& Biometrics Center, Fuwai Hospital, Chinese Academy of Medical Sciences, National Center for Cardiovascular Diseases, Beijing, China

Acknowledgements We are very grateful to the TIMI Study Group and the Duke Clinical Research Institute for their contributions in the design, conduct and data analyses of CAMl registry. We also want to thank all the investigators and coordinators for their great work and active participation. We thank Ellen Knapp, PhD, from Liwen Bianji, Edanz Group China (www.liwenbianji.cn/ac), for editing the English text of a draft of this manuscript. We thank Yang Wang and Wei Li for statistical analysis.

Contributors CS and RF were major contributors in writing the manuscript. KD and YY contributed substantially to the conception and design of the study. JY, HX, XG, HW and SL revised it critically for important intellectual content. XF contributed to analysis and interpretation of data.

Funding This work was supported by CAMS Innovation Fund for Medical Sciences (CIFMS) (2016-I2M-1-009), the Twelfth Five-Year Planning Project of the Scientific and Technological Department of China (2011BAl11B02), and 2014 Special fund for scientific research in the public interest by the National Health and Family Planning Commission of the People's Republic of China (No. 201402001).

Competing interests None declared.

Patient consent for publication Not required.

Ethics approval This study was approved by the institutional review board central committee at Fuwai Hospital, NCCD of China (approval ID: 2012-431).

Provenance and peer review Not commissioned; externally peer reviewed.

Data availability statement Data are available on reasonable request. 
Open access This is an open access article distributed in accordance with the Creative Commons Attribution Non Commercial (CC BY-NC 4.0) license, which permits others to distribute, remix, adapt, build upon this work non-commercially, and license their derivative works on different terms, provided the original work is properly cited, appropriate credit is given, any changes made indicated, and the use is non-commercial. See: http://creativecommons.org/licenses/by-nc/4.0/.

\section{REFERENCES}

1. Peto R, Lopez AD, Boreham J, et al. Mortality from tobacco in developed countries: indirect estimation from national vital statistics. Lancet 1992;339:1268-78.

2. Iversen B, Jacobsen BK, Løchen M-L. Active and passive smoking and the risk of myocardial infarction in 24,968 men and women during 11 year of follow-up: the Tromsø study. Eur J Epidemiol 2013;28:659-67.

3. Helmers C. Short and long-term prognostic indices in acute myocardial infarction. A study of 606 patients initially treated in a coronary care unit. Acta Med Scand Suppl 1973;555:7-26.

4. Aune E, Røislien J, Mathisen M, et al. The 'smoker's paradox' in patients with acute coronary syndrome: a systematic review. BMC Med 2011;9:97.

5. Kirtane AJ, Kelly CR. Clearing the air on the 'smoker's paradox'*. J Am Coll Cardiol 2015;65:1116-8.

6. Gurbel PA, Bliden KP, Logan DK, et al. The influence of smoking status on the pharmacokinetics and pharmacodynamics of clopidogrel and prasugrel: the paradox study. J Am Coll Cardiol 2013;62:505-12.

7. Shen L, Peterson ED, Li S, et al. The association between smoking and long-term outcomes after non-ST-segment elevation myocardial infarction in older patients. Am Heart J 2013;166:1056-62.

8. Rakowski T, Siudak Z, Dziewierz A, et al. Impact of smoking status on outcome in patients with ST-segment elevation myocardial infarction treated with primary percutaneous coronary intervention. J Thromb Thrombolysis 2012;34:397-403.

9. Grundtvig M, Hagen TP, Amrud ES, et al. Mortality after myocardial infarction: impact of gender and smoking status. Eur J Epidemiol 2011;26:385-93.

10. Tan NS, Goodman SG, Cantor WJ, et al. Comparison of the efficacy of pharmacoinvasive management for ST-segment elevation myocardial infarction in smokers versus non-smokers (from the trial of routine angioplasty and stenting after fibrinolysis to enhance reperfusion in acute myocardial infarction). Am J Cardiol 2014;114:955-61.

11. Goto K, Nikolsky E, Lansky AJ, Kenji G, Eugenia N, et al. Impact of smoking on outcomes of patients with ST-segment elevation myocardial infarction (from the HORIZONS-AMI trial). Am J Cardiol 2011;108:1387-94

12. Howe M, Leidal A, Montgomery D, et al. Role of cigarette smoking and gender in acute coronary syndrome events. Am J Cardiol 2011;108:1382-6.

13. Allahwala UK, Murphy JC, Nelson GIC, et al. Absence of a 'smoker's paradox' in field triaged ST-elevation myocardial infarction patients undergoing percutaneous coronary intervention. Cardiovasc Revasc Med 2013;14:213-7.

14. Bucholz EM, Beckman AL, Kiefe $\mathrm{Cl}$, et al. Smoking status and life expectancy after acute myocardial infarction in the elderly. Heart 2016;102:133-9.

15. Kang S-H, Suh J-W, Choi D-J, et al. Cigarette smoking is paradoxically associated with low mortality risk after acute myocardial infarction. Nicotine Tob Res 2013;15:1230-8.

16. Elosua R, Vega G, Rohlfs I, et al. Smoking and myocardial infarction case-fatality: hospital and population approach. Eur J Cardiovasc Prev Rehabil 2007;14:561-7.

17. Canto JG, Kiefe Cl, Rogers WJ, et al. Atherosclerotic risk factors and their association with hospital mortality among patients with first myocardial infarction (from the National Registry of myocardial infarction). Am J Cardiol 2012;110:1256-61.

18. Gupta T, Kolte D, Khera S, et al. Smoker's paradox in patients with ST-Segment elevation myocardial infarction undergoing primary percutaneous coronary intervention. J Am Heart Assoc 2016;5.

19. Xu H, Li W, Yang J, et al. The China acute myocardial infarction (CAMI) registry: a national long-term registry-research-education integrated platform for exploring acute myocardial infarction in China. Am Heart J 2016;175:193-201.

20. Thygesen K, Alpert JS, Jaffe AS, et al. Third universal definition of myocardial infarction. Eur Heart J 2012;33:2551-67.

21. Quality Improvement for Institutions. Data powering performance. Available: http://www.NCDR.com

22. Weintraub WS, Karlsberg RP, Tcheng JE, et al. ACCF/AHA 2011 key data elements and definitions of a base cardiovascular vocabulary for electronic health records: a report of the American College of cardiology Foundation/American heart association Task force on clinical data standards. Circulation 2011;124:103.

23. Cannon CP, Brindis RG, Chaitman BR, et al. 2013 ACCF/AHA key data elements and definitions for measuring the clinical management and outcomes of patients with acute coronary syndromes and coronary artery disease: a report of the American College of cardiology Foundation/American heart association task force on clinical data standards (writing committee to develop acute coronary syndromes and coronary artery disease clinical data standards). Circulation 2013;127:1052-89.

24. Little RJ, D'Agostino R, Cohen ML, et al. The prevention and treatment of missing data in clinical trials. N Engl J Med 2012;367:1355-60.

25. Weisz G, Cox DA, Garcia E, et al. Impact of smoking status on outcomes of primary coronary intervention for acute myocardial infarction-the smoker's paradox revisited. Am Heart 2005;150:358-64.

26. Sukiennik A, Koziński M, Debska-Kozińska K, et al. Smokers versus non-smokers undergoing percutaneous transluminal coronary angioplasty: the impact of clinical and procedural characteristics on in-hospital mortality. Cardiol J 2007;14:482-92.

27. Peng L, Zhang L, Yang J, et al. Joint effects of CYP2C19*2 and smoking status on clopidogrel responsiveness in patients with acute coronary syndrome. Int J Cardiol 2015;180:196-8.

28. Reed GW, Cannon CP, Waalen J, et al. Influence of smoking on the antiplatelet effect of clopidogrel differs according to dosing strategy: insights from the GRAVITAS trial. J Am Coll Cardiol 2013;61:E1917.

29. Zhang M, Liu X, Wang L, et al. Cigarette smoking might weaken the prognostic significance of cytochrome P450 2C19*2 polymorphism in acute myocardial infarction patients. $J \mathrm{Cell} \mathrm{Mol} \mathrm{Med}$ 2016;20:1247-54.

30. Yousef A-M, Arafat T, Bulatova NR, et al. Smoking behaviour modulates pharmacokinetics of orally administered clopidogrel. $J$ Clin Pharm Ther 2008;33:439-49.

31. Gurbel PA, Bliden KP, Logan DK, et al. The influence of smoking status on the pharmacokinetics and pharmacodynamics of clopidogrel and prasugrel. J Am Coll Cardiol 2013;62:505-12.

32. Symons R, Masci PG, Francone M, et al. Impact of active smoking on myocardial infarction severity in reperfused ST-segment elevation myocardial infarction patients: the smoker's paradox revisited. Eur Heart J 2016;37:2756-64.

33. Shen L, Peterson ED, Li S, et al. The association between smoking and long-term outcomes after non-ST-segment elevation myocardial infarction in older patients. Am Heart J 2013;166:1056-62.

34. Honda T, Fujimoto K, Miyao $\mathrm{Y}$, et al. Current cigarette smoking is an independent risk factor for subacute stent thrombosis in acute myocardial infarction patients. J Cardiol 2014;63:358-64.

35. Montalescot G, Sechtem U, Achenbach S, et al. 2013 ESC guidelines on the management of stable coronary artery disease: the task force on the management of stable coronary artery disease of the European Society of cardiology. Eur Heart J 2013;34:2949-3003.

36. Miyazaki T, Ashikaga T, Ohigashi $\mathrm{H}$, et al. Impact of smoking on coronary microcirculatory resistance in patients with coronary artery disease. Int Heart J 2015;56:29-36. 